\title{
O PAPEL DO FARMACÊUTICO NA PROMOÇÃO DA SAÚDE NO ÂMBITO DA ATENÇÃO BÁSICA
}

\section{Natalia Gava Peruchi}

\section{INTRODUÇÃO}

Os serviços de Atenção Básica de Saúde são a porta de entrada do cidadão ao Sistema de Saúde Pública, por meio de esclarecimentos, orientações e consultas eles disponibilizam informações e cuidados para a população, atuando inclusive na prevenção de doenças e epidemias. Neste sentido, percebe-se que estes serviços são responsáveis pela promoção da saúde da comunidade e, por conseguinte contribuem para a conquista e preservação da qualidade de vida destas pessoas.

Vale frisar que a promoção de saúde não deve ser compreendida somente como a prevenção de doenças, ela envolve também a prevenção de acidentes (de trânsito, domésticos e de trabalho), os riscos de violência, bem como o tratamento e a reabilitação ${ }^{(1)}$.

Destaca-se que Segundo a Organização Mundial da Saúde (OMS), qualidade de vida (QV) é: “a percepção do indivíduo de sua posição na vida, no contexto cultural e no sistema de valores nos quais ele vive e em relação a seus objetivos, expectativas, padrões e preocupações»(2). Em outras palavras, atuar diretamente na promoção da saúde incide positivamente na qualidade de vida das pessoas.

A precariedade do sistema público de saúde brasileiro, associada à falta de informações precisas, frequentemente levam a população ao uso inadequado dos medicamentos, ou mesmo a automedicação, o que pode trazer graves problemas ao paciente, tumultuar ainda mais os pronto-atendimentos e onerar os cofres públicos ${ }^{(3)}$.

Neste contexto, o papel do farmacêutico torna-se fundamental para o atendimento e esclarecimento da população. Ressalta-se que a atuação deste profissional vem sendo ampliada nas Unidades Básicas de Saúde (UBS), uma vez que o farmacêutico ao participar da equipe multidisciplinar dessas Unidades pode interagir de maneira mais direta e efetiva com o paciente e com os demais profissionais da equipe ${ }^{(3,4)}$.

A interação do farmacêutico com o paciente possibilita conhecer suas peculiaridades e necessidades, com vistas a orientá-lo sobre a maneira adequada de usar o medicamento, sobre os eventuais efeitos colaterais e principalmente sobre a importância da sua dispensação 
correta. Além disso, visa diminuir o hábito do brasileiro de estocar o medicamento que "sobrou" do tratamento para usá-lo (ou oferecê-lo para algum conhecido) da próxima vez que sentir os mesmos sintomas ${ }^{(5,6)}$.

No tocante aos profissionais da equipe multidisciplinar, formada nas USB, esta interação permite adquirir e compartilhar saberes, enriquecendo e fortalecendo o conhecimento de toda a equipe, o que, por conseguinte leva ao melhor atendimento ao paciente $^{(3,7)}$. No que tange mais especificamente ao farmacêutico nas UBS, cabe destacar a oportunidade de promover um maior controle dos medicamentos, o que assegura a sua disponibilidade e consequentemente o seu acesso ao paciente ${ }^{(3,8)}$. Deste modo, observa-se que a atuação do farmacêutico nas UBSs é de suma importância para a promoção da saúde e da qualidade de vida da população atendida. Além disso, é relevante enfatizar que as UBSs são a porta de entrada para o Sistema Único de Saúde de grande parcela da população, fato que demonstra a necessidade da prestação de um serviço "mínimo" de esclarecimento desses indivíduos/pacientes, inclusive no que diz respeito à medicação. Tal perspectiva ressalta ainda mais a importância do farmacêutico participar das equipes multidisciplinares da UBSs.

Neste sentido, a escolha desta temática justifica-se pela importância que o farmacêutico tem para sociedade, já que o presente estudo busca conhecer de uma forma mais profunda e por meio de pesquisas realizadas em várias partes do Brasil, o papel do farmacêutico na promoção da saúde e da qualidade de vida dos pacientes. Ademais, o esclarecimento da sociedade servirá para fiscalizar e cobrar uma atuação mais efetiva deste profissional nas UBSs. Tal medida é importante uma que $90 \%$ da população do Brasil automedica-se, como foi constatado pelo Ministério da Saúde, que também informa que entre 2010 e 2015, 60 mil pessoas foram hospitalizadas em decorrência da automedicação. O Conselho Federal de Farmácia também evidenciou que desde 1994, os medicamentos são os principais agentes causadores de intoxicação ${ }^{(9)}$.

Ademais, o estudo deste tema é relevante para os profissionais de Farmácia que também precisam conscientizar-se sobre a ampliação de suas atribuições nos serviços de saúde pública do país, principalmente da responsabilidade na promoção da saúde e da qualidade de vida dos pacientes das UBSs, que na maioria das vezes carece de informações adequadas e corretas sobre os medicamentos.

No entanto, alguns estudos, dentre eles os realizados por Bovo, Wisniewski e Morskei (2009) e por Galato (2008) e seus colaboradores, ainda demonstram que a função desempenhada pelos profissionais de Farmácia nas UBSs limita-se ao controle do estoque e a 
distribuição do medicamento prescrito pelo médico ao paciente ${ }^{(10,11)}$. Deste modo, percebe-se que o objetivo principal da Assistência Farmacêutica nessas Unidades - contribuir para a realização de um serviço de saúde pública integral, que promova o bem-estar e a qualidade de vida do paciente não está sendo alcançado, haja vista que o farmacêutico continua preso a função burocrática (distribuição de medicamentos) em detrimento a uma interação maior com o paciente, na qual esse poderia ser esclarecido sobre o uso adequado do medicamento, seus efeitos (inclusive colaterais e adversos) e a importância da sua dispensação correta ${ }^{(8)}$.

Nesta perspectiva, o objetivo principal do artigo é identificar a contribuição do farmacêutico participante das equipes multidisciplinares das UBS, na promoção da saúde e da qualidade de vida da população atendida. Além de: Verificar as atribuições do farmacêutico nas UBS; Conhecer as características do uso de medicamentos; Levantar junto à literatura os aspectos positivos da medicação racional para a população atendida pelas UBS.

\section{MÉTODO}

De acordo com os objetivos estabelecidos, esse estudo configura-se como uma revisão bibliográfica de caráter descritivo. Assim, os dados que alicerçam o trabalho foram coletados por meio da técnica bibliográfica, logo a pesquisa limitou-se a literatura (impressa e digitalizada) que permeia o tema.

No presente estudo, foram consultados livros e artigos publicados em periódicos e no meio digital, tomando como palavras-chave: papel do farmacêutico no Sistema Único de Saúde; papel do farmacêutico nas Unidades Básicas de Saúde; papel do farmacêutico na promoção de saúde; papel do farmacêutico na promoção da qualidade vida; e uso racional de medicamentos. Ressalta-se que o levantamento bibliográfico obedeceu às etapas previstas pela revisão integrativa, proposta por Ganong: formulação da hipótese e da questão de pesquisa; determinação dos critérios de inclusão e exclusão; organização dos dados em conformidade aos objetivos estabelecidos; apresentação da revisão integrativa dos artigos pesquisados; e discussão e interpretação dos resultados ${ }^{(12)}$.

Para sumarizar e organizar as publicações consultadas utilizou-se o instrumento oferecido por Nicolussi ${ }^{(13)}$ : um quadro no qual se identifica o título, ano de publicação, periódico, país, e características metodológicas. Foram estabelecidos com critério de inclusão os artigos: estarem nas bases de dados Scientific Electronic Library Online (SCIELO), Pubmed, Literatura Latino Americana e do Caribe em Ciências da Saúde (LILACS) e 
Biblioteca Regional de Medicina (BIREME); constarem as palavras-chave (papel do farmacêutico no Serviço Único de Saúde; papel do farmacêutico nas Unidades Básicas de Saúde; papel do farmacêutico na promoção de saúde; papel do farmacêutico na promoção da qualidade vida; e uso racional de medicação); terem sido publicados entre os anos 2005 2018; ter textos completos disponíveis em português.

E como critérios de exclusão: duplicidade de artigos: permanecerá o primeiro encontrado na base de dados; não possuir palavras-chave; artigos anteriores aos anos estabelecidos para a pesquisa; não ter disponível o texto para leitura na integra, em português.

Para a análise dos dados adotou-se a abordagem qualitativa, uma vez que ela se concentrou nos conceitos, argumentos e resultados obtidos em outros estudos que focalizam a temática, aqui, discutida. Conforme Turato, o método qualitativo tem o "fim comum de criar um modelo de entendimento profundo de ligações entre elementos, isto é, de falar de uma ordem que é invisível ao olhar comum"(14). Em outras palavras, esta abordagem não considera índices numéricos ou percentuais, mas se baseia em interpretações, argumentações e teorias.

\section{RESULTADOS}

Como este estudo fundamenta-se na revisão de literatura, buscou-se seguir rigorosamente os critérios de inclusão e exclusão estabelecidos para a seleção das publicações, que são apresentadas no Quadro 1. Ao todo foram selecionados 21 artigos, sendo que 13 continham 2 palavras-chaves no mesmo manuscrito; 06 uma palavra-chave e somente 02 artigos tinham as três palavras-chave. No entanto, é relevante ressaltar que um dos artigos que contém a maior quantidade das palavras-chave (3), não pertence ao banco de dados selecionados por este estudo, mas ao periódico de uma instituição de ensino superior - Revista Científica FAEMA. As demais publicações, constantes do Quadro, contêm uma e duas e três palavras-chave.

Ainda é importante informar que mais quatro (4) publicações com duas palavras-chave e duas (2) publicações com 1 palavra-chave também foram encontradas na pesquisa, todavia pertenciam a instituições de ensino e ao próprio Conselho Regional de Farmácia (Minas Gerais e São Paulo), logo não participam do quadro.

Quadro 1 - Publicações Selecionadas

\begin{tabular}{|c|c|c|c|c|c|}
\hline Ano & País & Título & Periódico & Metodologia & Resultados \\
\hline 2006 & Brasil & $\begin{array}{lr}\text { Concepções } & \text { do } \\
\text { profissional farmacêutico }\end{array}$ & $\begin{array}{c}\text { Revista Brasileira } \\
\text { de Ciências }\end{array}$ & $\begin{array}{l}\text { Entrevistas } \\
\text { semiestruturadas com }\end{array}$ & $\begin{array}{lr}\text { Foi } & \text { observado } \\
\text { que } & \text { atualmente } \\
\end{array}$ \\
\hline
\end{tabular}




\begin{tabular}{|c|c|c|c|c|c|}
\hline & & $\begin{array}{l}\text { sobre a assistência } \\
\text { farmacêutica na unidade } \\
\text { básica de saúde: } \\
\text { dificuldades e elementos } \\
\text { para a mudança }\end{array}$ & Farmacêuticas & $\begin{array}{l}\text { os farmacêuticos das } \\
\text { farmácias das UBS } \\
\text { de Ribeirão Preto } \\
\text { (SP) }\end{array}$ & $\begin{array}{l}\text { vigora nas UBSs } \\
\text { de Ribeirão Preto } \\
\text { (SP) uma gestão } \\
\text { burocrática dos } \\
\text { medicamentos, } \\
\text { sem controle de } \\
\text { estoques. }\end{array}$ \\
\hline 2007 & Brasil & $\begin{array}{l}\text { Qualidade dos } \\
\text { medicamentos contendo } \\
\text { dipirona encontrados nas } \\
\text { residências de Araraquara } \\
\text { e sua relação com a } \\
\text { atenção farmacêutica }{ }^{(15)}\end{array}$ & $\begin{array}{l}\text { Revista Brasileira } \\
\text { de Ciências } \\
\text { Farmacêuticas }\end{array}$ & $\begin{array}{ll}\text { Aplicação } & \text { de } \\
\text { formulários em } 477 \\
\text { residências de um } \\
\text { bairro no município } \\
\text { de Araraquara (SP) }\end{array}$ & $\begin{array}{l}\text { A maioria dos } \\
\text { pesquisados } \\
\text { guarda em casa } \\
\text { medicamentos a } \\
\text { base de Dipirona, } \\
\text { sendo que estes } \\
\text { apresentaram } \\
\text { queda } \\
\text { qualidade, } \\
\text { inclusive com } \\
\text { casos observados } \\
\text { de proliferação de } \\
\text { fungos } \\
\text { bactérias. }\end{array}$ \\
\hline 2007 & Brasil & 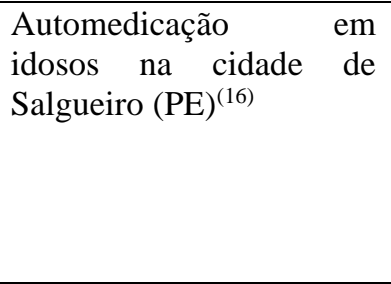 & $\begin{array}{l}\text { Revista Brasileira } \\
\text { Epidemiol. }\end{array}$ & $\begin{array}{l}\text { Estudo de corte } \\
\text { transversal realizado } \\
\text { na zona urbana no } \\
\text { município } \\
\text { Salgueiro }(\mathrm{PE}) .\end{array}$ & $\begin{array}{l}\text { Mulheres entre } \\
60-70 \text { anos, com } \\
\text { baixa } \\
\text { escolaridade se } \\
\text { automedicam } \\
\text { mais (analgésicos } \\
\text { e antipiréticos). }\end{array}$ \\
\hline 2007 & Brasil & $\begin{array}{lr}\text { Possibilidades } & \text { de } \\
\text { contribuição } & \text { do } \\
\text { farmacêutico para } & \text { a } \\
\text { promoção da saúde } & \end{array}$ & $\begin{array}{c}\text { Ciência e Saúde } \\
\text { Coletiva }\end{array}$ & Revisão bibliográfica & $\begin{array}{lr}\text { O uso irracional } \\
\text { de medicamentos } \\
\text { hoje é } \\
\text { problema } \\
\text { saúde pública, } \\
\text { logo } & \text { o } \\
\text { farmacêutico } & \text { é } \\
\text { importante } & \text { para } \\
\text { informar } & \text { e } \\
\text { acompanhar } & \text { os } \\
\text { pacientes } & \text { das } \\
\text { UBSs, com vistas } \\
\text { a melhorar este } \\
\text { quadro. }\end{array}$ \\
\hline 2008 & Brasil & $\begin{array}{l}\text { A habilidade de } \\
\text { comunicação com o } \\
\text { paciente no processo de } \\
\text { atenção farmacêutica }^{(18)}\end{array}$ & $\begin{array}{l}\text { Trab. Educ. } \\
\text { Saúde }\end{array}$ & Revisão bibliográfica & $\begin{array}{lr}\text { O farmacêutico } \\
\text { na sua relação } \\
\text { com o paciente } \\
\text { deve atuar como } \\
\text { um facilitador } \\
\text { para } \\
\text { aprendizagem do } \\
\text { paciente } \\
\text { tocante ao uso } \\
\text { racional no } \\
\text { medicamentos. }\end{array}$ \\
\hline 2008 & Brasil & $\begin{array}{l}\text { A dispensação de } \\
\text { medicamentos: uma } \\
\text { reflexão sobre o processo } \\
\text { para } \\
\text { identificação e resolução } \\
\begin{array}{lr}\text { de } & \text { prevencão, } \\
\text { relacionados } & \text { problemas }\end{array}\end{array}$ & $\begin{array}{l}\text { Revista Brasileira } \\
\text { de Ciências } \\
\text { Farmacêuticas }\end{array}$ & $\begin{array}{l}\text { Pesquisa qualitativa } \\
\text { baseada na pesquisa- } \\
\text { ação }\end{array}$ & $\begin{array}{l}\text { O farmacêutico } \\
\text { nas UBSs deve } \\
\text { atuar na } \\
\text { farmacovigilância } \\
\text { e na } \\
\text { farmacoterapia, } \\
\text { para tanto deve }\end{array}$ \\
\hline
\end{tabular}




\begin{tabular}{|c|c|c|c|c|c|}
\hline & & farmacoterapia $^{(11)}$ & & & $\begin{array}{lr}\text { estar } & \text { preparado } \\
\text { para } & \text { essas } \\
\text { funções. } & \\
\end{array}$ \\
\hline 2009 & Brasil & $\begin{array}{l}\text { Atenção Farmacêutica: } \\
\text { papel do farmacêutico na } \\
\text { promoção da saúde }\end{array}$ & Biosaúde & Revisão bibliográfica & $\begin{array}{l}\text { A Atenção } \\
\text { Farmacêutica é } \\
\text { nova no sistema } \\
\text { público de saúde, } \\
\text { mas tende a } \\
\text { ajudar os } \\
\text { pacientes, } \\
\text { principalmente } \\
\text { no que tange ao } \\
\text { uso racional da } \\
\text { medicação. }\end{array}$ \\
\hline 2013 & Brasil & $\begin{array}{l}\text { Assistência farmacêutica } \\
\text { em unidades básicas de } \\
\text { saúde do município de } \\
\text { Parnamerim }(\mathrm{RN})^{(19)}\end{array}$ & $\begin{array}{l}\text { Catussaba Revista } \\
\text { Científica da } \\
\text { Escola de Saúde } \\
\text { UP }\end{array}$ & $\begin{array}{l}\text { Pesquisa exploratória } \\
\text { com aplicação de } \\
\text { formulários com } \\
\text { entrevista aos } 26 \\
\text { diretores das UBS de } \\
\text { Parnamerim (RN) }\end{array}$ & $\begin{array}{l}\text { O serviço } \\
\text { farmacêutico, em } \\
\text { Parnamerim (RN) } \\
\text { é deficitário no } \\
\text { que diz respeito } \\
\text { ao } \\
\text { armazenamento e } \\
\text { dispensação dos } \\
\text { medicamentos. }\end{array}$ \\
\hline 2015 & Brasil & $\begin{array}{l}\text { Automedicação e o uso } \\
\text { irracional de } \\
\text { medicamentos:o papel do } \\
\text { profissional farmacêutico } \\
\text { no combate a essas } \\
\text { práticas }^{(6)}\end{array}$ & Revista UNIVAP & Revisão bibliográfica & $\begin{array}{l}\text { O farmacêutico } \\
\text { deve atuar como } \\
\text { orientador e } \\
\text { agente sanitário, } \\
\text { contribuindo para } \\
\text { o uso } \\
\text { racional de } \\
\text { medicamentos, } \\
\text { com vistas a } \\
\text { minimizar os } \\
\text { problemas } \\
\text { relacionados ao } \\
\text { uso inadequado } \\
\text { de fármacos. }\end{array}$ \\
\hline 2015 & Brasil & \begin{tabular}{l}
\multicolumn{3}{c}{ Serviços farmacêuticos na } \\
atenção primária no \\
município do Rio de \\
Janeiro: um estudo de \\
avaliabilidade $^{(20)}$
\end{tabular} & Saúde Debate & $\begin{array}{l}\text { Pesquisa documental } \\
\text { e entrevistas } \\
\text { semiestruturadas com } \\
\text { profissionais que } \\
\text { atuam na Assistência } \\
\text { farmacêutica do } \\
\text { município do Rio de } \\
\text { Janeiro }\end{array}$ & $\begin{array}{l}\text { A avaliação dos } \\
\text { serviços } \\
\text { farmacêuticos nas } \\
\text { UBSs } \\
\text { importante para a } \\
\text { construção de um } \\
\text { modelo de ação } \\
\text { técnica adequada } \\
\text { a cada realidade. }\end{array}$ \\
\hline 2016 & Brasil & $\begin{array}{l}\text { Promoção do uso racional } \\
\text { de medicamentos: uma } \\
\text { proposta de modelo } \\
\begin{array}{l}\text { avaliativo da gestão } \\
\text { municipal }^{(21)}\end{array}\end{array}$ & Saúde Debate & $\begin{array}{l}\text { Revisão de literatura } \\
\text { e técnica de } \\
\text { conferência } \\
\text { consenso }\end{array}$ & $\begin{array}{l}\text { É relevante que a } \\
\text { gestão da UBS } \\
\text { crie mecanismos } \\
\text { de promoção do } \\
\text { uso racional de } \\
\text { medicamentos. }\end{array}$ \\
\hline 2017 & Brasil & $\begin{array}{l}\text { A contribuição do } \\
\text { farmacêutico para a } \\
\text { promoção do acesso e uso } \\
\text { racional de medicamentos } \\
\text { essenciais no SUS }\end{array}$ & $\begin{array}{c}\text { Ciência e Saúde } \\
\text { Coletiva }\end{array}$ & $\begin{array}{l}\text { Estudo descritivo, } \\
\text { transversal, realizado } \\
\text { em unidade de } \\
\text { atenção primária do } \\
\text { município de São } \\
\text { Paulo }\end{array}$ & $\begin{array}{l}\text { A atuação do } \\
\text { farmacêutico na } \\
\text { UBS contribuiu } \\
\text { para a redução da } \\
\text { falta de } \\
\text { medicamentos e } \\
\text { para a melhora da } \\
\text { qualidade na }\end{array}$ \\
\hline
\end{tabular}




\begin{tabular}{|c|c|c|c|c|c|}
\hline & & & & & $\begin{array}{l}\text { prescrição dos } \\
\text { mesmos. }\end{array}$ \\
\hline 2017 & Brasil & $\begin{array}{l}\text { Indicadores relacionados } \\
\text { ao uso racional de } \\
\text { medicamentos e seus } \\
\text { fatores associados }\end{array}$ & $\begin{array}{l}\text { Revista de Saúde } \\
\text { Pública }\end{array}$ & $\begin{array}{l}\text { Estudo transversal } \\
\text { realizado em amostra } \\
\text { representativa de } \\
\text { municípios do } \\
\text { incluídos }\end{array}$ & $\begin{array}{l}\text { A presença do } \\
\text { farmacêutico na } \\
\text { UBS apresentou } \\
\text { mais chance para } \\
\text { a transmissão de } \\
\text { informações } \\
\text { sobre a } \\
\text { dispensação } \\
\text { adequada dos } \\
\text { medicamentos. }\end{array}$ \\
\hline 2018 & Brasil & $\begin{array}{l}\text { O papel do profissional } \\
\text { farmacêutico na } \\
\text { promoção da saúde e do } \\
\text { uso racional de } \\
\text { medicamentos }^{(24)} \text {. }\end{array}$ & $\begin{array}{c}\text { Revista Científica } \\
\text { FAEMA }\end{array}$ & Revisão bibliográfica & $\begin{array}{l}\text { A promoção da } \\
\text { saúde é uma das } \\
\text { atribuições do } \\
\text { farmacêutico nas } \\
\text { UBSs e deve } \\
\text { englobar a } \\
\text { orientação e o } \\
\text { acompanhamento } \\
\text { farmacoterapeuta. }\end{array}$ \\
\hline
\end{tabular}

Fonte: Autora (2018).

Observou-se que o uso racional dos medicamentos é um dos objetivos da Atenção Farmacêutica, que por sua vez busca a promoção da saúde e o bem-estar do paciente, inserindo-se na função técnico-assistencial desempenhada pelo farmacêutico. Considerandose que no Brasil há mais de 80 milhões de indivíduos que se automedicam ${ }^{(24)}$.

Essa prática se tornou um problema potencialmente prejudicial à saúde da população, devido ao uso indiscriminado de medicamentos como podemos destacar os over the conter (OTC), ou de venda livre, por exemplo: Paracetamol, Ácido Acetilsalicílico, Dipirona Sódica, Ibuprofeno, entre outros, que podem causar diversas consequências como mascarar sintomas de diversas doenças, interferências em resultados clínicos ${ }^{(24)}$.

Neste contexto, a Agência Nacional de Vigilância Sanitária (ANVISA) prevê que o farmacêutico atenda diretamente o paciente com o fim de avaliá-lo e orientá-lo sobre a farmacoterapia prescrita pelo médico, para tanto deve levar em conta as necessidades e peculiaridades de cada paciente, incluindo a possibilidade da ocorrência de reações adversas, a não aderência ao tratamento e eventuais prescrições inadequadas ${ }^{(25)}$.

\section{DISCUSSÃO}

Como foi apresentado nos resultados, os artigos pesquisados concluíram de uma forma geral que a automedicação, o uso e a dispensação inadequadas de medicamentos é bastante comum entre os brasileiros, fato que evidencia a relevância do papel do farmacêutico no 
esclarecimento da população sobre este tema e demonstra a sua importância na promoção da saúde e, por conseguinte na melhora da qualidade de vida dos pacientes.

No artigo, “A Dispensação de Medicamentos: uma Reflexão sobre o Processo para Prevenção, Identificação e Resolução de Problemas Relacionados à Farmacoterapia”, observou-se que o farmacêutico ao esclarecer sobre a dispensação dos medicamentos pode "prevenir, identificar e resolver problemas relacionados à farmacoterapia"(11). Todavia, para os pesquisadores, é necessário que este profissional desenvolva suas habilidades de comunicação e favoreça uma relação de empatia com o paciente para que, além de informá-lo possa efetivamente promover a mudança de hábito que levará consequentemente a hábitos mais saudáveis, que garantirão seu bem-estar, promovendo uma melhora na sua qualidade de vida.

A importância das habilidades de comunicação do farmacêutico também foi investigada no estudo, “A Habilidade de Comunicação com o Paciente no Processo de Atenção Farmacêutica”, realizado por Possamai e Dacoreggio (2008), no qual foi ressaltada a relevância do farmacêutico como facilitador da aprendizagem do paciente no que diz respeito ao uso racional dos medicamentos. Considerando-se que, para os pesquisadores, "o acesso de um paciente aos serviços de saúde e aos próprios medicamentos não é suficiente para garantir o êxito de um tratamento", sendo fundamental a intervenção educativa do profissional de Farmácia para esclarecer sobre a prescrição, o armazenamento, o uso e a dispensação dos medicamentos $^{(18)}$. Deste modo, acredita-se que o farmacêutico estará atuando de forma efetiva na promoção da saúde e na melhora da qualidade de vida do paciente.

Corroborando com a perspectiva do papel do farmacêutico da UBS, como agente na promoção da saúde da comunidade na qual a Unidade está inserida, Vieira (2013), em seu artigo, "Possibilidades de Contribuição do Farmacêutico para a Promoção da Saúde", constatou que o uso inadequado de medicamentos é um problema de saúde pública, que pode ser amenizado pelo farmacêutico das UBSs à medida que ele informe os pacientes, mais detalhadamente, sobre a prescrição, administração e a dispensação correta dos medicamentos. A autora explica que esta é uma das atribuições deste profissional "na promoção da saúde, principalmente através da disposição de um serviço de farmácia com qualidade (e neste aspecto incluem-se a orientação e o acompanhamento farmacêutico) e, da educação em saúde, de fácil acesso à população" ${ }^{(17)}$. Neste sentido, observa-se que a autora vincula a atuação do farmacêutico diretamente a promoção da saúde da comunidade atendida pela UBS, o que pode ser visto como uma importante atribuição deste profissional. 
Achados semelhantes foram encontrados por Monteiro e Lacerda (2016) e publicados no artigo, "Promoção do Uso Racional de Medicamentos: uma Proposta de Modelo Avaliativo da Gestão Municipal"(21); por Lima e seus colaboradores (2017) ${ }^{(23)}$ e por Santana $(2018)^{(24)}$, fato que demonstra que o farmacêutico nas UBSs pode contribuir como um agente ativo na promoção da saúde dos pacientes à medida que ele se aproxima mais do paciente para orientá-lo e acompanhá-lo sobre como administrar os medicamentos e como dispensá-los após o uso. Ao mesmo tempo em que deve organizar a farmácia da UBS (solicitação, armazenagem correta, orientação na prescrição, controle de estoque, etc.), que por sua vez também contribuirá para a promoção da saúde da comunidade de uma forma geral, já que atenderá a população de maneira mais eficiente e eficaz.

O artigo publicado por Serafim e suas colaboradoras (2007), "Qualidade dos Medicamentos Contendo Dipirona Encontrados nas Residências de Araraquara e sua Relação com a Atenção Farmacêutica", demonstrou que as pessoas têm o costume de guardar medicamentos (neste caso a Dipirona) e usá-los posteriormente quando sintomas semelhantes (na percepção do paciente) aparecerem, embora desconheçam que a qualidade (incluindo a efetividade do princípio ativo) destes fármacos pode estar comprometida, o que além de não “curá-lo" também poderá acarretar outros problemas a sua saúde ${ }^{(15)}$. As autoras explicam:

Constatou- se que a maioria é guardada dentro de armários na cozinha e ignoram o tempo de armazenamento do medicamento depois de aberto, assim como a sua exposição a altas temperaturas, luz solar ou artificial e umidade; muitas vezes os frascos não são corretamente fechados, sendo o conta-gotas colocado diretamente em contato com pias e mesas ou mesmo com as mãos; entretanto não possuem medicamentos vencidos em suas residências $(93,3 \%)$ e o descarte é realizado diretamente ao lixo $(79 \%)^{(15)}$.

Estes resultados demonstram que esta prática identificada no estudo, como comum, vai no caminho contrário à promoção de saúde, haja vista que compreende-se que promover saúde é prevenir, doenças, acidentes e violência por meio da informação e de intervenções ${ }^{(1)}$, logo fica clara a importância do farmacêutico como agente esclarecedor da comunidade na qual a UBS está situada e, por isso motivador de uma vida mais saudável.

O estudo realizado em Pernambuco, por Sá, Barros e Sá (2007) e publicado no artigo, “Automedicação em Idosos na Cidade de Salgueiro", evidenciou que a prática da automedicação é mais comum entre as mulheres e entre os idosos com nenhuma ou baixa escolaridade, o que pode sugerir que a falta de informação, sobretudo no que diz respeito aos efeitos danosos da automedicação, é uma das causas desta prática, embora tenha sido constatado nesta pesquisa que os motivos mais frequentes apresentados pelos pesquisados 
sejam a dor, a febre, a diarreia, a pressão alta e a tosse ${ }^{(16)}$. Observa-se que estes pacientes não percebem que estes são sintomas que podem sugerir doenças graves que precisam ser identificadas, o que certamente levará ao agravamento do caso e, por conseguinte a piora do paciente. Neste mesmo contexto, a pesquisa constatou que, segundo o Sistema Nacional de Informações Tóxico-farmacológicas (SINITOX), há um número significativo de registros de intoxicação por medicamentos, decorrentes da automedicação e de erros de administração dos medicamentos $^{(16)}$.

Estes achados evidenciam mais uma vez a importância do papel do farmacêutico nas UBSs, para o esclarecimento da comunidade sobre os riscos da automedicação e para o ensino da administração adequada dos fármacos, embora os autores salientem que a prática da automedicação é universal e está presente nas mais diversas sociedades e culturas, independentemente do grau de desenvolvimento socioeconômico das mesmas. Entretanto, os autores ressaltam a relevância da informação correta, haja vista que, para eles, está ocorrendo a "medicalização da saúde, na qual a mesma vem sendo puramente associada ao uso de medicamentos para a manutenção da saúde" ${ }^{(16)}$. Neste sentido, percebe-se que a informação pode contribuir para desfazer este entendimento equivocado sobre medicamentos e saúde e, por conseguinte melhorar a qualidade de vida dos pacientes, uma vez que a saúde diverge totalmente do uso exagerado de medicamentos e, sobretudo da automedicação.

O artigo, "Automedicação e o Uso Irracional de Medicamentos: o Papel do Profissional Farmacêutico no Combate a essas Práticas”, desenvolvido por Fernandes e Cembranelli (2015), demonstrou achados semelhantes aos encontrados por Sá, Barros e Sá (2007), ou seja, reconheceu a importância do farmacêutico como agente de promoção da saúde à medida que pode atuar juntamente ao corpo de profissionais da UBS no esclarecimento dos pacientes sobre o uso racional de medicamentos. Os autores elucidam que "o profissional farmacêutico deve assumir a responsabilidade de promotor da saúde e contribuir a favor do uso racional de medicamento, favorecendo a população brasileira e desafogando a saúde pública do país"(6).

Outro ponto observado nos artigos analisados foi à importância do farmacêutico nas UBSs, no que tange ao armazenamento adequado, ao controle de estoque e à melhoria da qualidade das prescrições de medicamentos. Este achado foi mencionado no trabalho de Araujo (2006), “Concepções do Profissional Farmacêutico sobre a Assistência Farmacêutica na Unidade Básica de Saúde: Dificuldades e Elementos para a Mudança"(3); bem como no estudo realizado por Melo e Castro (2017) e publicado no artigo, “A Contribuição do 
Farmacêutico para a Promoção do Acesso e Uso Racional de Medicamentos Essenciais no SUS", no qual relataram que "na integração do farmacêutico à equipe multiprofissional, ele passa a assumir papel relevante na redução de problemas relacionados a medicamentos e na melhoria da qualidade das prescrições médicas"(22).

No entanto, é importante salientar que no estudo realizado por Galato e seus colaboradores (2008) foi evidenciado que alguns farmacêuticos que trabalham nas farmácias da UBSs nem sempre estão preparados para atender a população, no tocante ao esclarecimento sobre a prescrição e o uso racional da medicação. Os pesquisadores afirmam que "quando o farmacêutico exerce sua função de prestar serviços na farmácia, muitas vezes, apresenta deficiências de conhecimento que podem gerar distorções do seu verdadeiro papel”(11) . Tal fato denota que a capacitação do farmacêutico deva ser uma estratégia de saúde pública, uma vez que a ideia é a prevenção de doenças e o uso racional de medicamentos.

Corroborando com este entendimento, o estudo realizado por Bovo, Wisniewski e Morskei (2009), cujo os resultados foram publicados no artigo,“Atenção Farmacêutica: Papel do Farmacêutico na Promoção da Saúde", foi constatado que a participação do farmacêutico nas equipes multidisciplinares das UBSs tem por objetivo melhorar a orientação da comunidade assistida sobre o uso racional dos medicamentos, contudo é fundamental que a formação deste profissional também seja direcionada para a prática e para o atendimento ao público, com conhecimentos amplos que possam ajudar o paciente na administração dos medicamentos $^{(10)}$.

Além disso, “os órgãos de saúde pública também devem atentar para essa nova prática paciente [informar, orientar e acompanhar os pacientes], uma vez que ela envolve uma metodologia simples, barata e que pode, além de trazer inúmeros benefícios à saúde, gerar economia"(10). Estes achados demonstram que o farmacêutico pode contribuir para a promoção da saúde, desde que seja tecnicamente preparado para este tipo de intervenção e que o próprio sistema de saúde disponibilize condições (tempo, espaço, etc.) para que o devido atendimento ao paciente seja realizado.

Vale frisar que esta disponibilização de condições para a efetiva intervenção do farmacêutico nas UBSs também foi ressaltada no estudo de caso, "Assistência Farmacêutica em Unidades Básicas de Saúde do Município de Parnamerim” realizado por Vieira, Cruz e Cunha (2013), no qual foi observado que "o serviço farmacêutico é deficitário: nos itens armazenamento e dispensação", sendo que o trabalho do profissional de Farmácia é comprometido pela ausência de uma estrutura física adequada ${ }^{(19)}$. Resultados semelhantes 
foram constatados por Pereira, Luiza, Cruz (2015) e publicados no artigo, "Serviços Farmacêuticos na Atenção Primária no Município do Rio de Janeiro: um Estudo de Avaliabilidade"(20).

Diante destes achados, percebe-se que a atuação do farmacêutico nas UBSs, por meio da orientação e acompanhamento dos pacientes quanto ao uso racional dos medicamentos e a orientação para uma prescrição de qualidade desses medicamentos - pode ser fundamental na promoção da saúde da comunidade, no entanto o próprio sistema de saúde deve prover as condições necessárias para que a atuação do farmacêutico, vá além da "distribuição" dos medicamentos (prática comum nas UBSs), para torná-lo efetivamente um agente na promoção da saúde e da qualidade de vida da comunidade.

\section{CONCLUSÃO}

Observou-se que os artigos pesquisados na literatura demonstram que o farmacêutico ao atuar nas UBSs pode contribuir para a promoção da saúde na comunidade à medida que esclarece dúvidas e ensina os pacientes a utilizarem os medicamentos de forma racional, bem como a dispensação adequada dos mesmos, considerando-se ainda que esta atuação pode contribuir para a redução da prática da automedicação, um problema visto como de saúde pública no Brasil, dado aos índices elevados desta prática.

Entretanto, também foi constatado que as UBSs precisam disponibilizar as condições adequadas - espaço físico e tempo para o atendimento ao paciente - para que o farmacêutico possa conduzir seu trabalho, tendo em vista que muitas Unidades não possuem nem estrutura física para o armazenamento correto dos medicamentos.

Além disso, verificou-se que os cursos da formação do profissional de Farmácia devem prepará-lo para o atendimento ao público, uma vez que muitos destes profissionais não têm esta habilidade, de suma importância para o desenvolvimento de uma relação baseada na empatia e na simplicidade para transmitir o conhecimento, isto é, a informação sobre o uso racional dos medicamentos. Por fim, acredita-se que o farmacêutico possa promover a saúde e, por conseguinte melhorar a qualidade de vida dos pacientes das UBSs, desde que sejam atendidas estas condições. 


\section{REFERÊNCIAS}

1Buss PM. Promoção da saúde da família.Programa Saúde da Família. [Internet]. 2012 dez: 50-63. \{acesso em 2019 maio]. Disponível em: <http://bvsms.saude.gov.br/bvs/is_digital/is_0103/IS23\%281\%29021.pdf>

2 Haikal DS, Santa-Rosa TTA, Oliveira PLA, Sales LOS, Pereira AACA, Macedo CCS, Ferreira RC, Martins AMEBL, Ferreira EF. Qualidade de vida, satisfação e esforço/recompensa no trabalho, transtornos psíquicos e níveis de atividade física entre trabalhadores da atenção primária à saúde. Revista de APS. [Internet]. 2013 jul/dez; 16 (3): 301-312. [acesso em 2019 maio]. Disponível em: <http://aps.ufjf.emnuvens.com.br/aps/article/view/1549/748>.

3 Araujo ALA, Freitas O. Concepções do profissional farmacêutico sobre a assistência farmacêutica na unidade básica de saúde: dificuldades e elementos para a mudança. Revista Brasileira de Ciências Farmacêuticas. [Internet]. 2006 jan/mar; 42(1): 137-146. [acesso em 2018 mar]. Disponível em: <http://www.scielo.br/scielo.php?script=sci_arttext\&pid=S151693322006000100015>.

4 Ferreira RR, Nobrega JOT. Atuação do profissional farmacêutico na atenção básica de saúde. [Internet]. 2012;1-22. [acesso em 2018 jul]. Disponível em: <http://www.cpgls.pucgoias.edu.br/8mostra/Artigos/SAUDE\%20E\%20BIOLOGICAS/Atua $\% \mathrm{C} 3 \%$ A7\% $3 \%$ A3o\%20do\%20profissional $\% 20$ farmac\%C3\%AAutico\%20na\%20aten $\% \mathrm{C} 3$ $\%$ A7\% $3 \%$ A3o\%20b\%C3\%A1sica\%20de\%20sa\%C3\%BAde.pdf $>$.

5 Reis AMM. Atenção farmacêutica e promoção do uso racional de medicamentos. Centro de Estudo em Atenção Farmacêutica [Internet] 2002. [acesso em 2018 set]. Disponível em: http://www.ceatenf.ufc.br/Artigos/ATENFAR\%20e\%20URM\%20Adriano\%20Max.pdf.

6 Fernandes WS, Cembranelli JC. Automedicação e o uso irracional de medicamentos: o papel do profissional farmacêutico no combate a essas práticas. Revista UNIVAP. [Internet]. 2015 jul.; 21(37): 5-12. [acesso em 2018 mar]. Disponível em: <https://revista.univap.br/index.php/revistaunivap/article/view/265>.

7 Conselho Regional de Farmácia/Minas Gerais. A importância do farmacêutico no SUS: suas competências e atribuições nas ações de saúde pública. [Internet] 2011. [acesso em 2018 mar].

Disponível <http://www.crfmg.org.br/externo/profissional_empresa/downloads/2.pdf>. .

8 Brandão A. O que pode o farmacêutico. Pharmacia Brasileira. [internet] Conselho Federal de Farmácia. 2006 maio/jun; 28-37. [acesso em 2018 mar]. Disponível em: <http://www.cff.org.br/sistemas/geral/revista/pdf/14/28a37.pdf>.

9 Guedes A. Automedicação pode ter graves consequências. [Internet] Brasília: Senado Federal, 2017. [acesso em 2018 mar]. Disponível em: <https://www12.senado.leg.br/noticias/especiais/especial-cidadania/automedicacao-pode-tergraves-consequencias>. 
10 Bovo F, Wisniewski P, Morskei MLM. Atenção farmacêutica: papel do farmacêutico na promoção da saúde, Biosaúde, [Internet]. 2009 jan/jun; 11(1): 43-56. [acesso em 2018 mar]. Disponível

em:

<http://www.uel.br/revistas/uel/index.php/biosaude/article/view/24303/17900>.

11 Galato D. et. al. A dispensação de medicamentos: uma reflexão sobre o processo para prevenção, identificação e resolução de problemas relacionados à farmacoterapia. Revista Brasileira de Ciências Farmacêuticas. [Internet]. 2018 jul/set; 44(3): 465-475. [acesso em 2018 mar]. Disponível em: 〈http://www.scielo.br/pdf/rbcf/v44n3/a17v44n3.pdf>.

12 Ganong LH. Integrative reviews of nursing research. Res Nurs Health, [Internet]. 1987; 10(1):1-11. [acesso em 2018 jul]. Disponível em: <https://onlinelibrary.wiley.com/doi/abs/10.1002/nur.4770100103>.

13 Niicolussi AC. Qualidade de vida de pacientes com câncer de cólon e reto: uma revisão integrativa. [Dissertação] [Ribeirão Preto]. Escola de Enfermagem de Ribeirão Preto/USP; 2008. 209 p.

14 Turato ER. Métodos qualitativos e quantitativos na área de saúde: definições, diferenças e seus objetos de pesquisa. Revista de Saúde Pública [Internet]. 2005 jan./mar; 39(3):507-514. [acesso em 2018 mar]. Disponível em: <http://www.scielo.br/pdf/rsp/v39n3/24808.pdf>.

15 Serafim EOP et. al. Qualidade dos medicamentos contendo dipirona encontrados nas residências de Araraquara e sua relação com a atenção farmacêutica. Revista Brasileira de Ciências Farmacêuticas. [Internet]. 2007 jan/mar; 43:127-135, [acesso em 2018 mar]. Disponível em: 〈http://www.scielo.br/pdf/rbcf/v43n1/15.pdf>.

16 Sá MB, Barros JAC, Sá MPBO. Automedicação em idosos na cidade de Salgueiro - PE. Revista Brasileira Epidemiol, [Internet]. 2007; 10(1):75-85. [acesso em 2018 mar]. Disponível em: <http://www.scielo.br/pdf/rbepid/v10n1/08.pdf >.

17 Vieira FS. Possibilidades de contribuição do farmacêutico para a promoção da saúde. Ciência e Saúde Coletiva. [Internet]. 2007 jan/mar;12(1): 213-220. [acesso em 2018 mar]. Disponível em: <http://www.scielo.br/scielo.php?script=sci_arttext\&pid=S141381232007000100024>.

18 Possamai FP, Dacoreggio MS. A habilidade de comunicação com o paciente no processo de atenção farmacêutica. Trabalho, Educação e Saúde. [Internet]. 2008; 5(3):473-490. [acesso 2018 mar]. Disponível em: 〈http://www.scielo.br/pdf/tes/v5n3/08.pdf>.

19 Vieira AMP, Cruz APF, Cunha VF. Assistência farmacêutica em unidades básicas de saúde do município de Parnamirim (RN). Catussaba Revista Científica da Escola de Saúde UP. [Internet]. 2013 jan;2(1):35-49.[acesso em 2018 set]. Disponível em: <https://repositorio.unp.br/index.php/catussaba/article/view/178>.

20 Pereira NC, Luiza VL, Cruz MM. Serviços farmacêuticos na atenção primária no município do Rio de Janeiro: um estudo de avaliabilidade. Saúde Debate. [Internet]. 2015 mar/abr; 39(105):451-468. [acesso em 2018 set]. Disponível em: $<$ http://www.scielo.br/scielo.php?pid=S0103$11042015000200451 \&$ script=sci_abstract $\&$ tlng $=$ pt $>$. 
21 Monteiro ER, Lacerda JT. Promoção do uso racional de medicamentos: uma proposta de modelo avaliativo da gestão municipal. Saúde Debate. [Internet]. 2016 out/dez; 40(111): 101116. [acesso em 2018 set]. Disponível em: <http://www.scielo.br/pdf/sdeb/v40n111/01031104-sdeb-40-111-0101.pdf>.

22 Melo DO, Castro LLC. A contribuição do farmacêutico para a promoção do acesso e uso racional de medicamentos essenciais no SUS. Ciência e Saúde Coletiva. [Internet]. 2017; 22(1):235-244. [acesso em 2018 set]. Disponível em: <http://www.scielo.br/pdf/csc/v22n1/1413-8123-csc-22-01-0235.pdf>.

23 Lima GM et. al. Indicadores relacionados ao uso racional de medicamentos e seus fatores associados. Revista de Saúde Pública. [Internet]. 2017; (51): 2-23. [acesso em 2018 jul]. Disponível em: http:<//www.scielo.br/pdf/rsp/v51s2/pt_0034-8910-rsp-S1518-51-s287872017051007137.pdf>.

24 Santana KS. O papel do profissional farmacêutico na promoção da saúde e do uso racional de medicamentos. Revista Científica FAEMA. [Internet]. 2018 jan/jul; 9(1):399-412. [acesso em 2018 jul]. Disponível em: <http://www.faema.edu.br/revistas/index.php/RevistaFAEMA/article/view/538>.

25 Anvisa. Agência Nacional de Vigilância Sanitária. Farmacovigilância: conceitos de farmacovigilância. [Internet] 2008. [acesso em 2018 mar]. Disponível em: <http://www.anvisa.gov.br/farmacovigilancia/conceito_glossario.htm>. 